\title{
Understanding the Spatial Distribution of Forest Fires in a Growing Urban Region: Socioeconomic Indicators Tell You More
}

\author{
Luca Salvati $^{*}$, Agostino Ferrara $^{2}$, Margherita Carlucci ${ }^{3}$ \\ ${ }^{1}$ Consiglio per la Ricerca e la Sperimentazione in Agricoltura, Centro per lo Studio delle Relazioni Pianta-Suolo \\ (CRA-RPS), Rome, Italy \\ ${ }^{2}$ School of Agricultural, Forest, Food and Environmental Sciences, University of Basilicata, Potenza, Italy \\ ${ }^{3}$ Department of Social and Economic Sciences, "Sapienza" University of Rome, Rome, Italy \\ Email: "luca.salvati@entecra.it
}

Received 3 January 2014; revised 3 February 2014; accepted 10 February 2014

Copyright $@ 2014$ by authors and Scientific Research Publishing Inc.

This work is licensed under the Creative Commons Attribution International License (CC BY).

http://creativecommons.org/licenses/by/4.0/

(c) (i) Open Access

\section{Abstract}

The present study analyzes the spatial distribution of 881 forest fires recorded during four recent years (2009-2012) in 59 municipalities of a Mediterranean region (Attica, Greece) characterized by high fire risk and relevant human pressure due to uneven urban expansion. The hypothesis that a defined fire profile (in terms of density, severity and land-use selectivity) on a local scale was associated to a specific set of socioeconomic and territorial variables, was tested explicitly using six fires' indicators and eight contextual indicators under a multivariate analysis framework. Analysis identified two main dimensions for both forest fires (dimension and selectivity) and the socioeconomic context (demographic variables associated to the urban-rural gradient and average income). Fire density and forest/pastures burnt areas did not correlated to any socioeconomic variable. At the same time, average declared income and elevation of each municipality did not correlated to any fires' variable. To the contrary, the average fire size, the percentage of burnt area per municipality and the proportion of cropland affected by fires correlated positively with the distance from the inner city and the total surface area of each municipality and negatively with the proportion of compact settlements, population density and growth. These results confirm the importance of the urban-rural divide determining the spatial distribution of forest fires in Attica while pointing out the modest influence of variables such as the socioeconomic status of resident population.

\section{Keywords}

Socio-Demographic Changes; Declared Income; Indicators; Multivariate Analysis; Fire Risk;

\footnotetext{
${ }^{*}$ Corresponding author.
} 


\section{Mediterranean Region}

\section{Introduction}

In fragile Mediterranean environments characterized by the millenary interaction between man and nature, the spatial distribution and expansion of urban settlements traditionally shaped the neighboring landscape in a more effective way than it was done by the action of biophysical gradients such as elevation or the distance from the sea (Antrop [1]; Catalàn et al. [2]; Polyzos et al. [3]; Salvati et al. [4]). Although southern European cities are usually regarded as representative examples of compact, dense and land-saving cities (Paul and Tonts [5]; Kasanko et al. [6]; Cakir et al. [7]), urban growth especially in the form of discontinuous, low density settlements, was found increasing in recent years [8]. Threatened by exurban development, peri-urban landscapes and, more in general, rural areas surrounding big cities are characterized by a variety of land-use classes, which are reflected in fragmented environments sensitive to fires and soil erosion (Arianoutsou [9]; Allen [10]; Badia-Perpinyà and Pallares-Barbera [11]; Briassouli [12]). Forest fires, especially big fires, are relevant events shaping the ecological fragility of the Mediterranean landscape, altering the structure, composition and diversity of landscapes and determining land degradation in certain environmental conditions with important consequences also for the social and economic local context (Christopoulou et al. [13]; Martìnez et al. [14]; Moreira et al. [15]). The hypothesis that a defined fire profile (in terms of density, severity and land-use selectivity) on a local scale was associated to a specific set of socioeconomic and territorial variables (e.g. [16]) was tested explicitly in the present study. By analyzing six fires' indicators and eight contextual indicators through a multivariate exploratory framework, we evaluated the spatial distribution of 881 forest fires recorded during four recent years (2009-2012) in 59 municipalities of a Mediterranean region (Attica, Greece) characterized by high fire risk and relevant human pressure [17]. Information derived from this analysis proves useful in planning local strategies for the containment of forest fires in peri-urban areas.

\section{Methods}

\subsection{Study Area}

The investigated area covers a large part of the administrative region of Attica, central Greece, extending for nearly $3000 \mathrm{~km}^{2}$ (Figure 1). According to the local authorities' reform enforced in 2011 (the so called "Kallikratis” law), the area was subdivided in 59 municipalities (including a municipality covering the entire Salamina island). The region mostly consists of mountains with the highest elevation reaching $1413 \mathrm{~m}$ in Mount Parnitha at only $25 \mathrm{~km}$ northwest Athens. Three coastal plains (Messoghia, Marathon and Thriasio) are located in the Attica region outside the urban area [4]. Population residing in the region amounted to 3.8 million people in 2011 with a density of 1248 inhabitants $/ \mathrm{km}^{2}$.

\subsection{Forest Fire Data}

This study was based on 881 records of the Hellenic Fire Brigade on individual forest fires occurred in the investigated area from 2009 to 2012. For each fire, the data set includes a field estimate of the burnt area, the date and hour of ignition, the municipalities of the ignition point or a description of the place of ignition (the name of the main road or similar information useful to the geo-referencing process); these information allowed to assign each fire to one of the 59 municipalities of the region. The database contains all fires that were recorded by the Fire Brigade, and is assumed to be enough complete and reliable down to the smallest fires. Density of fires was 0.29 events $/ \mathrm{km}^{2}$ during 2009-2012 with the average burned area per fire amounting to 28 hectares (Table 1 ). According to previous studies [18], fire size distribution in Attica was adequately described by a power-law over many orders of magnitude with nearly $80 \%$ fires $<1$ ha and only $1 \%>100$ ha. Like in most Mediterranean regions, the large majority of fires included in this analysis are human-caused rather than "natural” in origin and mainly concentrated during hot and dry months spanning from late spring to early autumn. The available database includes information on the surface area of different land-use classes affected by each fire event. Three classes were considered here: 1) forests and related natural habitats including maquis, garigue and shrublands, 2) cropland and 3) pastures. The 881 events examined in this study may be regarded as enough representative of the fire regime characterizing the region. The investigated time interval (2009-2012) include years with few but 


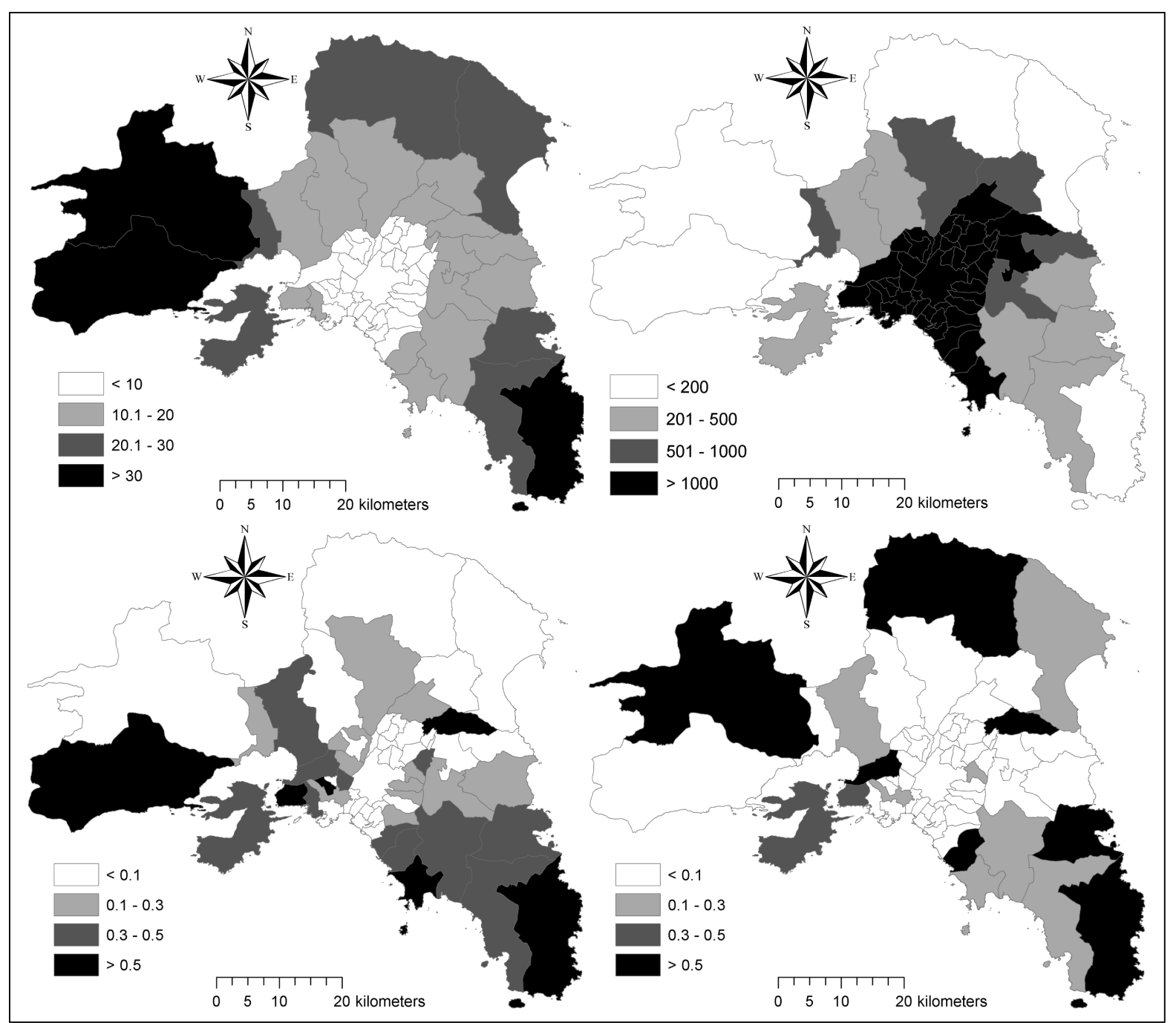

Figure 1. Maps describing selected characteristics of the investigated area (upper left: average municipality distance from Athens' centre [km]; upper right: population density [inhabitants $/ \mathrm{km}^{2}$ ]; lower left: density of forest fires [per year and $\mathrm{km}{ }^{2}$ ], lower right: percentage of burnt land on total municipal area [\%]).

Table 1. Fire statistics in the investigated area by year.

\begin{tabular}{cccccc}
\hline Variable & 2009 & 2010 & 2011 & 2012 & Total \\
\hline Number of fires & 184 & 304 & 194 & 199 & 881 \\
Burnt area $\left(\mathrm{km}^{2}\right)$ & 199.3 & 17.9 & 3.8 & 28.2 & 249.1 \\
Average fire size (ha) & 108.3 & 5.9 & 1.9 & 14.2 & 28.3 \\
Woodland (\%) & 50.2 & 25.0 & 68.6 & 55.8 & 49.3 \\
Cropland (\%) & 16.8 & 29.4 & 3.4 & 21.1 & 18.0 \\
Pastures (\%) & 25.4 & 41.7 & 24.2 & 22.9 & 26.3 \\
\hline
\end{tabular}

extremely severe events (2009), years with a high number of fires and moderate severity in terms of total area and forest land affected (2010), favorable years with a reduced number of events characterized by low fire severity (2011) and years with an intermediate fire profile (2012). According to meteorological data recorded in Thissio station (Athens) by the National Observatory of Athens (NOAA), the four years showed also an heterogeneous climatic pattern, with a relatively wet year (2009) and a hot and exceptionally dry year (2010) intermixed with years showing a normal climatic regime. 


\subsection{Indicators}

Six fires' indicators and eight socioeconomic variables were calculated at the municipal scale from data made available by Hellenic Statistic Authority, Ministry of the Environment and Ministry of Finance (Table 2). The selected indicators assess, on the one hand, fire density, severity and selectivity and, on the other hand, demographic and territorial characteristics along the urban-to-rural gradient, including population density and average income. The spatial unit of analysis adopted in this study allows evaluating changes in the spatial distribution of population along the urban-to-rural gradient by integrating information from different statistical and field surveys. Figure 1 illustrates the spatial distribution of four selected indicators in the study area.

\subsection{Statistical Analysis}

The spatial distribution of each studied indicator was explored through maps based on official municipality boundaries produced by Hellenic Statistical Authority in 2012. Municipalities with no fires observed along the investigated period were removed from further analysis. Two separate Principal Components Analyses were run to identify the main factors characterizing fire profile in Attica and socioeconomic and territorial characteristics of local municipalities. Factors with eigenvalues $>1$ were extracted and two separate plots of factor loadings and factor scores were produced. A non-parametric Spearman rank correlation analysis was carried out comparing the distribution of the six fire's indicators and the eight socioeconomic indicators in the studied municipalities testing at $p<0.05$ after Bonferroni's correction for multiple comparisons. Finally, a non-hierarchical cluster analysis (using Euclidean metric with Ward's agglomeration rule) was developed to identify similarities in the spatial distribution of the 14 indicators examined here.

\section{Results and Discussion}

Out of 59 municipalities considered, forest fires were recorded in 39 of them, the other 20 municipalities concentrating high-density settlements with few green spaces apart from small gardens and non-vegetated, abandoned open land. The resulting density of fires illustrated in Figure 1 showed a rather heterogeneous spatial pattern with peri-urban and accessible municipalities characterized by several small-sized fires while the percentage of burnt area on the total municipal surface indicates a contrasting spatial pattern with less accessible, rural municipalities characterized by severe (and sometimes repeated) burning. These findings suggest the existence of different fires' profiles on a local scale shaped by the changing socioeconomic context along the urban gradient. Principal Components Analyses applied separately to the two available datasets (fires' variables and socioeconomic variables) pointed out the importance of various interpretative dimensions on a local scale (Figure 2, upper left): as for fires' variables, PCA factor 1 (explaining 33\% of total variance) represents an axis of fire severity ordering municipalities according to AVGFSU, FIRSU\% and FIRDEN values. PCA factor 2 (accounting for 31\% of total variance) illustrates the opposition between strictly woodland fires and fires involving cropland and pastures with municipalities distributed primarily along this gradient (Figure 2, upper right): on average, fires with smaller size affected forest land more frequently than fires with larger size generally consuming more agricultural and pasture lands. Results of the PCA applied to the eight socioeconomic variables identified two relevant dimensions in the spatial organization of the investigated area. PCA factor 1 (explaining $54 \%$ of total variance) illustrates the urban-to-rural gradient described by population density and growth and the distance from the inner city of Athens (Figure 2, lower left) which separated local municipalities in two homogeneous groups (Figure 2, lower right). PCA factor 2 (accounting for 16\% of total variance) represents the economic disparities observed at the urban scale in Attica, pointing out the spatial polarization observed between rich and poor municipalities, in turn oriented along the elevation gradient (high and intermediate social classes tend to settle on upland municipalities around the main urban center). Based on a Spearman rank coefficients matrix (Table 3), the correlation analysis between fires' and socioeconomic variables indicates a complex spatial pattern based on fires' severity and the related land-use selectivity. Fire density and forest/ pastures burnt areas did not correlate to any socioeconomic variable. At the same time, the average declared income and the elevation class assigned to each municipality did not correlate to any fires' variable. To the contrary, the average fire size, the percentage of burnt area per municipality and the proportion of cropland affected by fires correlated positively with the distance from the inner city and the total surface area of each municipality and negatively with the proportion of compact settlements, population density and growth and the ratio of 
Table 2. List of variables investigated in the present study.

\begin{tabular}{|c|c|c|c|}
\hline Acronym & Indicator & Measurement unit & Primary data source \\
\hline \multicolumn{4}{|c|}{ Forest fires' variables } \\
\hline FIRDEN & Density of forest fires on total municipal area (2009-2012) & Fires per $\mathrm{km}^{2}$ & Hellenic Fire Brigade \\
\hline AVGFSU & Average fire size by municipality (2009-2012) & Hectare & Hellenic Fire Brigade \\
\hline FIRSU\% & Percentage of municipal area affected by fires (2009-2012) & Burnt area $/ \mathrm{km}^{2}$ & Hellenic Fire Brigade \\
\hline WOOD & Proportion of burnt forests on total burnt area (2009-2012) & $\%$ & Hellenic Fire Brigade \\
\hline CROP & Proportion of burnt cropland on total burnt area (2009-2012) & $\%$ & Hellenic Fire Brigade \\
\hline PAST & Proportion of burnt pastures on total burnt area (2009-2012) & $\%$ & Hellenic Fire Brigade \\
\hline \multicolumn{4}{|c|}{ Territorial and socioeconomic variables } \\
\hline DENPOP & Population density (2011) & Inhabitants $/ \mathrm{km}^{2}$ & Hellenic Statistic Authority \\
\hline DIST & Distance from Athens & $\mathrm{km}$ & Hellenic Statistic Authority \\
\hline VARDEM & Annual population growth rate (2001-2011) & $\%$ & Hellenic Statistic Authority \\
\hline POPRAT & The ratio of present to resident population (2011) & $\%$ & Hellenic Statistic Authority \\
\hline ADJBUI & The ratio of adjacent buildings on total buildings (2001) & $\%$ & Hellenic Statistic Authority \\
\hline SUPMUN & Municipality surface area & $\mathrm{km}^{2}$ & Ministry of the Environment \\
\hline ELEV & Elevation (0: lowland; 1 : upland municipalities) & Dummy & Ministry of the Environment \\
\hline INCOME & Average per-capita declared income (2011) & Euros & Ministry of Finance \\
\hline
\end{tabular}

Table 3. Non-parametric Spearman rank correlation coefficients between forest fires' variables and territorial/socioeconomic variables in the study area (bold indicates significant correlations at $p<0.05$ after Bonferroni's correction for multiple comparisons).

\begin{tabular}{|c|c|c|c|c|c|c|c|c|}
\hline Variable & DENPOP & DIST & VARDEM & POPRAT & ADJBUI & SUPMUN & ELEV & INCOME \\
\hline FIRDEN & -0.04 & 0.07 & 0.00 & 0.16 & 0.00 & -0.14 & 0.11 & -0.10 \\
\hline AVGFSU & -0.55 & 0.48 & -0.45 & 0.37 & -0.44 & 0.49 & 0.09 & -0.03 \\
\hline FIRSU\% & -0.55 & 0.51 & -0.40 & 0.47 & -0.38 & 0.45 & 0.09 & -0.13 \\
\hline WOOD & 0.24 & -0.21 & 0.33 & -0.25 & 0.23 & -0.27 & 0.22 & 0.11 \\
\hline CROP & -0.78 & 0.78 & -0.79 & 0.52 & -0.78 & 0.73 & -0.20 & 0.07 \\
\hline PAST & -0.10 & 0.08 & -0.11 & 0.20 & -0.02 & 0.17 & -0.15 & -0.21 \\
\hline
\end{tabular}

present to resident population. The dendrogram generated by a non-hierarchical cluster analysis using Euclidean distances with Ward's linkage agglomeration rule was illustrated in Figure 3. This analysis was aimed to identify similarities in the spatial distribution of the whole set of variables examined. This analysis was aimed to identify similarities in the spatial distribution of the whole set of variables examined. Ward's dendrogram identified two groups of variables (from FIRDEN to FIRSU\% and from WOOD to ADJBUI) suggesting a separation between fires observed on Athens' fringe and those recorded in the rural area surrounding the urban region. The former type of fires usually destroys small patches of (mainly forest) land in municipalities characterized by specific socioeconomic traits (medium-high population density in compact and semi-compact settlements, high average declared income, growing population determining higher anthropogenic pressure on fringe's land). The latter type of fires is characterized by high density and severity and low selectivity, being primarily associated to high land availability to edification and the prevalence of agricultural and pasture land.

\section{Conclusion}

Previous studies underlined that, across the Mediterranean basin, the spatial distribution of land-uses and the socio-demographic context may affect fire regimes, with population densification, deregulated urban expansion, 

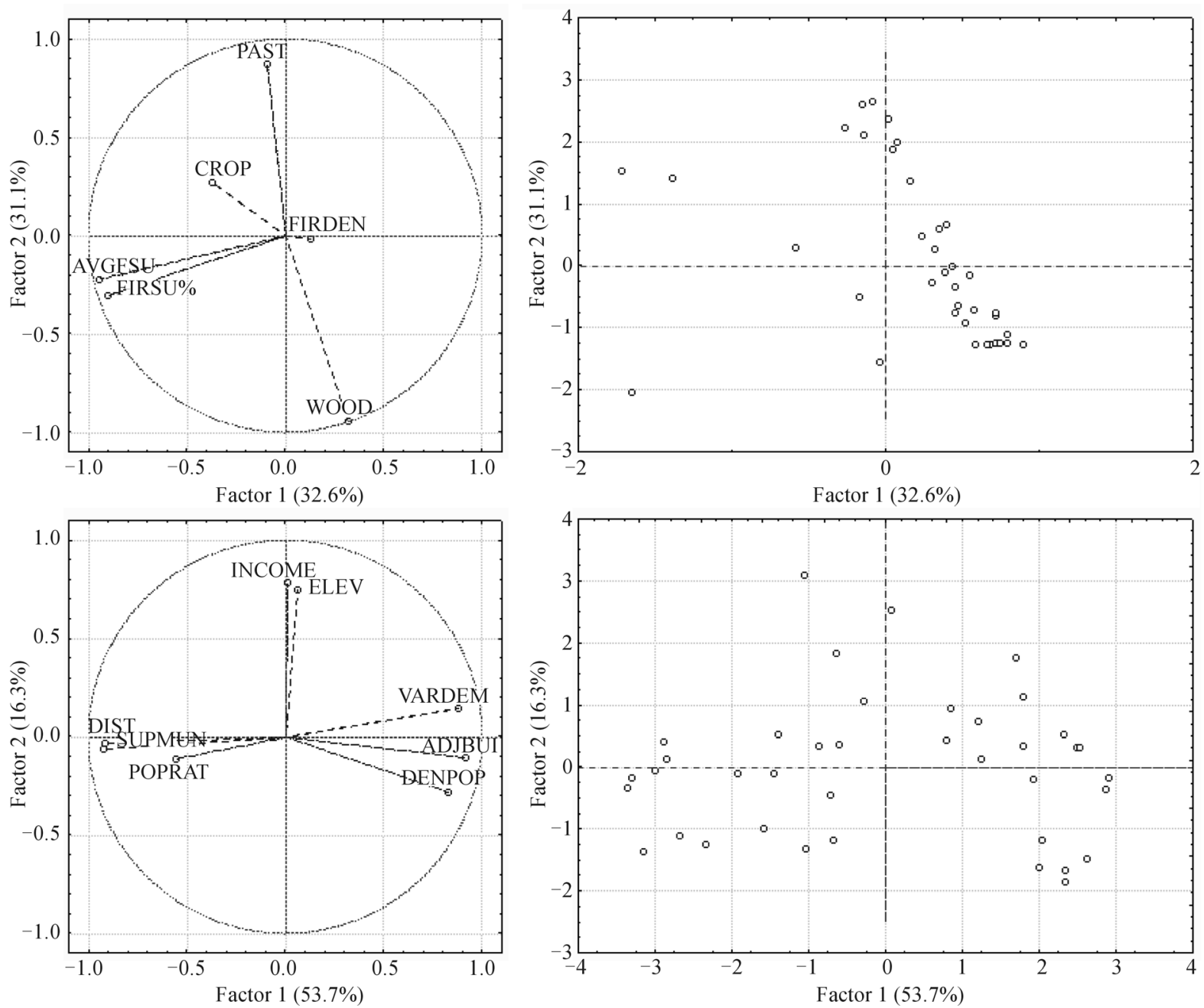

Figure 2. Principal components analysis results (left: factor loadings, right: factor scores; upper panel: forest fires’ variables; lower panel: territorial and socioeconomic variables).

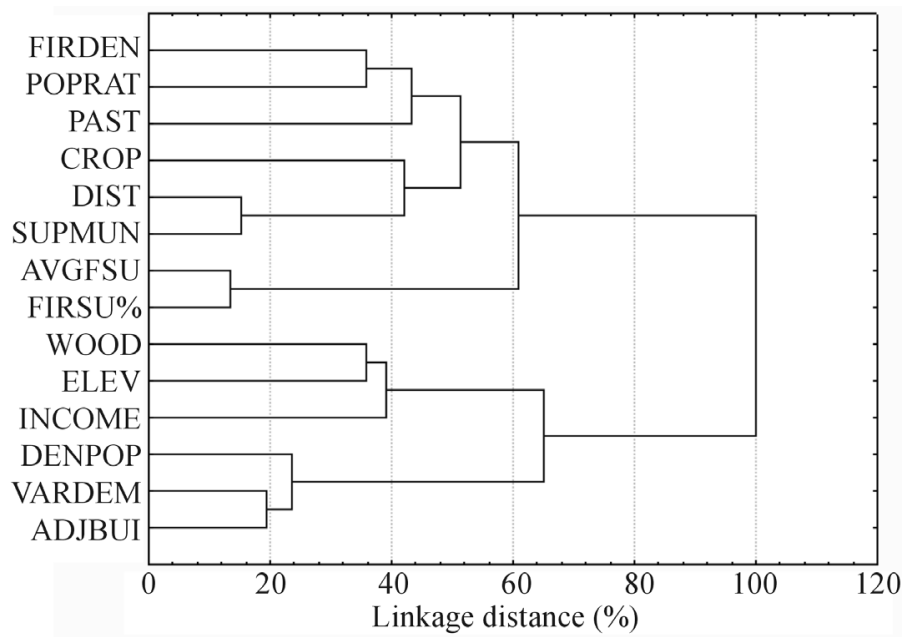

Figure 3. Non-hierarchical cluster analysis (Euclidean distances, Ward's agglomeration rule) evaluating similarity in the distribution of the investigated variables among municipalities in Attica. 
crop intensification, livestock density and land abandonment being the most important factors determining fire hazard (e.g. Pausas et al. [19]; Lampin-Maillet et al. [20]; Minetos and Polyzos [21]; Barbati et al. [22]). Our research partly confirms this theory by depicting the intimate relationship between defined fire profiles (severity and land-use selectivity) and specific socioeconomic variables in a Mediterranean peri-urban landscape. Using exploratory statistical analysis, we demonstrated that socio-demographic and economic indicators reflected in the urban-rural gradient of a large city region can provide insight in the analysis of forest fires' spatial distribution and structural characteristics. The indicators illustrated here may form the basis for an integrated monitoring system for fire risk. These variables, produced by official data sources, are easily and freely accessible on the web and can be mapped using administrative boundaries or interpolated to physiographic or vegetation homogeneous regions [23]. Remote sensing application and field survey data may also contribute to this information system [15]. Finally, the information collected in the present study may inform local-scale (i.e. municipal or district) plans for sustainable forestry at the wildland-urban interface [24] and fire suppression programs integrating monitoring, control and rapid interventions in the most vulnerable municipalities.

\section{Acknowledgements}

The financial support of "Sapienza" University of Rome ("Desert” project University funds) is kindly acknowledged.

\section{References}

[1] Antrop, M. (2004) Landscape Change and the Urbanization Process in Europe. Landscape and Urban Planning, 67, 9-26. http://dx.doi.org/10.1016/S0169-2046(03)00026-4

[2] Catalàn, B., Sauri, D. and Serra, P. (2008) Urban Sprawl in the Mediterranean? Patterns of Growth and Change in the Barcelona Metropolitan Region 1993-2000. Landscape and Urban Planning, 85, 174-184.

[3] Polyzos, S., Christopoulou, O., Minetos, D. and Leal Filho, W. (2008) An Overview of Urban-Rural Land Use Interactions in Greece. International Journal of Agricultural Resources, Governance and Ecology, 7, 276-296.

[4] Salvati, L., Sateriano, A. and Bajocco, S. (2013) To Grow or to Sprawl? Evolving Land Cover Relationships in a Compact Mediterranean City Region. Cities, 30, 113-121. http://dx.doi.org/10.1016/j.cities.2012.01.007

[5] Paul, V. and Tonts, M. (2005) Containing Urban Sprawl: Trends in Land Use and Spatial Planning in the Metropolitan Region of Barcelona. Journal of Environmental Planning and Management, 48, 7-35. http://dx.doi.org/10.1080/0964056042000308139

[6] Kasanko, M., Barredo, J.I., Lavalle, C., McCormick, N., Demicheli, L., Sagris, V. and Brezger, A. (2006) Are European Cities Becoming Dispersed? A Comparative Analysis of Fifteen European Urban Areas. Landscape and Urban Planning, 77, 111-130. http://dx.doi.org/10.1016/j.landurbplan.2005.02.003

[7] Cakir, G., Un, C., Baskent, E.Z., Kose, S., Sivrikaya, F. and Keles, S. (2008) Evaluating Urbanization, Fragmentation and Land Use/Cover Change Pattern in Istanbul City, Turkey from 1971 to 2002. Land Degradation and Development, 19, 663-675. http://dx.doi.org/10.1002/ldr.859

[8] European Environment Agency (2006) Urban Sprawl in Europe-The Ignored Challenge. EEA Report No. 10, Copenhagen. http://www.eea.europa.eu/publications/eea_report_2006_10

[9] Arianoutsou, M. (2001) Landscape Changes in Mediterranean Ecosystems of Greece: Implications for Fire and Biodiversity Issues. Journal of Mediterranean Ecology, 2, 165-178.

[10] Allen, A. (2003) Environmental Planning and Management of the Peri-Urban Interface: Perspectives on an Emerging Field. Environment \& Urbanization, 15, 135-147.

[11] Badia-Perpinyà, A. and Pallares-Barbera, M. (2006) Spatial Distribution of Ignitions in Mediterranean Periurban and Rural Areas: The Case of Catalonia. International Journal of Wildland Fire, 15, 187-196. http://dx.doi.org/10.1071/WF04008

[12] Briassouli, H. (1992) The Planning Uses of Fire: Reflections on The Greek Experience. Journal of Environmental Planning and Management, 35, 161-173. http://dx.doi.org/10.1080/09640569208711917

[13] Christopoulou, O., Polyzos, S. and Minetos, D. (2007) Peri-Urban and Urban Forests in Greece: Obstacle or Advantage to Urban Development? Management of Environmental Quality: An International Journal, 18, 382-395. http://dx.doi.org/10.1108/14777830710753794

[14] Martínez, J., Vega-García, C. and Chuvieco, E. (2009) Human-Caused Wildfire Risk Rating for Prevention Planning in Spain. Journal of Environmental Management, 90, 1241-1252. http://dx.doi.org/10.1016/j.jenvman.2008.07.005 
[15] Moreira, F., Viedma, O., Arianoutsou, M., Curt, T., Koutsias, N., Rigolot, E., Barbati, A., Corona, P., Vaz, P., Xanthopoulos, G., Mouillot, F. and Bilgili, E. (2011) Landscape-Wildfire Interactions in Southern Europe: Implications for Landscape Management. Journal of Environmental Management, 92, 2389-2402. http://dx.doi.org/10.1016/j.jenvman.2011.06.028

[16] Oliveras, I., Gracia, M., Moré, G. and Retana, J. (2009) Factors Influencing the Pattern of Fire Severities in a Large Wildfire under Extreme Meteorological Conditions in the Mediterranean Basin. International Journal of Wildland Fire, 18, 755-764. http://dx.doi.org/10.1071/WF08070

[17] Chorianopoulos, I., Pagonis, T., Koukoulas, S. and Drymoniti, S. (2010) Planning, Competitiveness and Sprawl in the Mediterranean City: The Case of Athens. Cities, 27, 249-259. http://dx.doi.org/10.1016/j.cities.2009.12.011

[18] Bajocco, S. and Ricotta, C. (2008) Evidence of Selective Burning in Sardinia (Italy): Which Land-Cover Classes Do Wildfires Prefer? Landscape Ecology, 23, 241-248. http://dx.doi.org/10.1007/s10980-007-9176-5

[19] Pausas, J.G., Llovet, J., Rodrigo, A. and Vallejo, V.R. (2008) Are Wildfires a Disaster in the Mediterranean Basin? A Review. International Journal of Wildland Fire, 17, 713-723. http://dx.doi.org/10.1071/WF07151

[20] Lampin-Maillet, C., Jappiot, M., Long, M., Bouillon, C., Morge, D. and Ferrier, J.-P. (2010) Mapping Wildland-Urban Interfaces at Large Scales Integrating Housing Density and Vegetation Aggregation for Fire Prevention in the South of France. Journal of Environmental Management, 91, 732-741. http://dx.doi.org/10.1016/j.jenvman.2009.10.001

[21] Minetos, D. and Polyzos, S. (2010) Deforestation Processes in Greece: A Spatial Analysis by Using an Ordinal Regression Model. Forest Policy and Economics, 12, 457-472. http://dx.doi.org/10.1016/j.forpol.2010.02.011

[22] Barbati, A., Corona, P., Salvati, L. and Gasparella, L. (2013) Natural Forest Expansion into Suburban Countryside: Gained Ground for a Green Infrastructure? Urban Forestry \& Urban Greening, 12, 36-43. http://dx.doi.org/10.1016/j.ufug.2012.11.002

[23] European Commission (2011) Forest Fires in Europe, Middle East and North Africa 2012. EUR 26048, Publication Office of the European Union, Luxembourg. http://forest.jrc.ec.europa.eu/effis/reports/annual-fire-reports/

[24] Theobald, D.M. and Romme, W.H. (2007) Expansion of the US Wildland-Urban Interface. Landscape and Urban Planning, 83, 340-354. http://dx.doi.org/10.1016/j.landurbplan.2007.06.002 